\title{
A study of the pinch performance and subjective satisfaction with chopsticks of different lengths
}

\author{
Rain Chen ${ }^{1, a}$, Min Wang ${ }^{2}$ and Jo-Han Chang ${ }^{3}$ \\ ${ }^{1}$ Department of Visual Communication Design, Southern Taiwan University of Science and Technology, \\ Tainan City 710, Taiwan \\ ${ }^{2}$ Graduate School of Digital Content and Applied Design, Southern Taiwan University of Science and Technology, \\ Tainan City 710, Taiwan \\ ${ }^{3}$ Department of Industrial Design, National Taipei University of Technology, Taipei City 106, Taiwan
}

\begin{abstract}
Total 40 college students (16 males and 24 females), with an average age of 22 , were surveyed in this study. The participants are highly familiar with the use of chopsticks and were tested with their handedness (95\% of the participants are right-handers and $5 \%$ of the participants are left-handers). The control variable in this study is chopsticks 6 millimeters in diameter. Instruments used in this experiment were four pairs of chopsticks of different lengths: $120 \mathrm{~mm}$ (Type A), $150 \mathrm{~mm}$ (Type B), $180 \mathrm{~mm}$ (Type C), $210 \mathrm{~mm}$ (Type D). Each participant was requested to randomly use these 4 pairs of chopsticks to pick up peanuts (10 millimeters in diameter). Least Significant Difference (LSD) was utilized for measuring quantity of pinched peanuts and participants' satisfaction at four different types of chopsticks.. The research results revealed that quantity of pinched peanuts showed significant difference $(\mathrm{p}=0.017)$ when the length of chopsticks changed from $120 \mathrm{~mm}$ to $180 \mathrm{~mm}$. In terms of satisfaction, it presented significant difference $(\mathrm{p}=0.001)$ among four types, and participants showed higher satisfaction at longer chopsticks. Correlation Analysis will be further applied in future study, with a larger quantity and a random approach, and the future study can be used to find out the most appropriate chopsticks length for the reference of chopsticks manufacturers.
\end{abstract}

\section{Introduction}

At least 1.5 billion people worldwide use chopsticks every day as eating utensils. Chopsticks were developed in the Eastern World due to living conditions and environmental factors in ancient times while knives and forks were their counterparts in the Western World. Since chopsticks are not commonly used in Western countries, ergonomic studies of them are relatively scarce in comparison with those of forks and knives (Riley and Cochran, 1980; Cochran and Riley, 1986a, 1986b).

In terms of chopstick-related researches, the effect of chopstick lengths on the pinch performance was the first issue that had been systematically studied. Hsu and other researchers believed that the length of chopsticks has a significant influence on their performance in pinching food and suggested that the best chopstick lengths for adults and children are $240 \mathrm{~mm}$ and $180 \mathrm{~mm}$ respectively (Hsu and $\mathrm{Wu}, 1991$ ). Chan's study suggested that the optimum chopstick diameter is around $6 \mathrm{~mm}$ (Chan, 1999). $\mathrm{Wu}$, believed that the best diameter of chopstick tip is $4 \mathrm{~mm}$, whereas he discovered the

\footnotetext{
${ }^{\mathrm{a}}$ Corresponding author : ocean@ stust.edu.tw
} 
influence of chopstick tip angle on food-pinching performance and advised on a $2^{\circ}$ tip angle as a complement to $4 \mathrm{~mm}$ diameter tip (Wu, 1995) .

Chopsticks on the market have a variety of cross-section shapes, but circular and square shapes are the most common types. Chen classified chopsticks according to their appearances such as a tip with carved grooves and cross-section shapes such as circular and square. Then he put forward six common combinations for experiment. It was discovered that chopsticks with circular cross-section shape have better food-pinching performance and chopsticks with carved grooves on tips have better performance of pinching food than those without grooves (Chen, 1998). Wu and other researchers also compared the performance of four cross-section shapes of chopstick handles, which were: circular, rectangular, hexagonal, and rounded square, and it was discovered that cross-section shapes which are circular and rounded square have the best performance (Wu and Tsai, 2012). A summary of the related studies is shown in Table 1.

Table 1. A summary of studies of chopsticks.

\begin{tabular}{|c|c|c|c|c|}
\hline Researcher & $\begin{array}{l}\text { Independent } \\
\text { Variables }\end{array}$ & Control Variables & Criteria Measured & Outcome \\
\hline $\begin{array}{l}\text { Hsu and } \\
\text { Wu (1991) }\end{array}$ & $\begin{array}{l}* \text { Chopstick lengths } \\
\text { for adults: } 180 \\
\mathrm{~mm}, 210 \mathrm{~mm}, 240 \\
\mathrm{~mm}, 270 \mathrm{~mm}, 300 \\
\mathrm{~mm}, 330 \mathrm{~mm} \\
{ }^{*} \text { Chopstick lengths } \\
\text { for children: } \\
150 \mathrm{~mm}, 180 \mathrm{~mm} \text {, } \\
210 \mathrm{~mm}, 240 \mathrm{~mm} \text {, } \\
270 \mathrm{~mm}, 300 \mathrm{~mm}\end{array}$ & $\begin{array}{l}\text { *Handle diameter: } \\
6 \mathrm{~mm} \\
\text { *Tip length: } 80 \mathrm{~mm} \\
\text { *Tip diameter: } \\
3.5 \mathrm{~mm} \\
\text { *Tip slant angle: } 1^{\circ}\end{array}$ & $\begin{array}{l}\text { *Food-pinching } \\
\text { performance } \\
\text { *Performance of } \\
\text { pulling food apart } \\
\text { *Subjective } \\
\text { evaluation } \\
\text { *Subjective ranking }\end{array}$ & $\begin{array}{l}\text { *Optimum length } \\
\text { for children: } \\
180 \mathrm{~mm} \\
\text { *Optimum length } \\
\text { for adults: } 240 \mathrm{~mm} \\
\text { *Optimum length } \\
\text { for restaurants: } \\
210 \mathrm{~mm}\end{array}$ \\
\hline Wu (1995) & $\begin{array}{l}\text { *Handle diameters: } \\
\text { 4mm, } 6 \mathrm{~mm}, 8 \mathrm{~mm} \\
\text { *Tip slant angles: } \\
0^{\circ}, 2^{\circ}, 4^{\circ}, 6^{\circ} \text { 。 }\end{array}$ & $\begin{array}{l}\text { *Total length: } \\
210 \mathrm{~mm} \\
\text { *Handle length: } \\
180 \mathrm{~mm} \\
\text { *Tip length: } 30 \mathrm{~mm} \\
\text { (disposable } \\
\text { chopsticks) }\end{array}$ & $\begin{array}{l}\text { *Food-pinching } \\
\text { performance } \\
\text { *Performance of } \\
\text { pulling food apart } \\
\text { *Food-cutting } \\
\text { performance } \\
\text { *Food-piercing } \\
\text { performance } \\
\text { *Subjective } \\
\text { evaluation } \\
\text { *Subjective ranking }\end{array}$ & $\begin{array}{l}\text { *Optimum handle } \\
\text { diameter: } 6 \mathrm{~mm} \\
\text { *Optimum tip } \\
\text { diameter: } 4 \mathrm{~mm} \\
\text { *Optimum slant } \\
\text { angle of tip: } 2^{\circ}\end{array}$ \\
\hline $\begin{array}{l}\text { Chan } \\
(1999)\end{array}$ & $\begin{array}{l}\text { *Handle diameters: } \\
2 \mathrm{~mm}, 4 \mathrm{~mm}, 6 \mathrm{~mm} \text {, } \\
8 \mathrm{~mm}, 10 \mathrm{~mm} \\
\text { *Target: red beans, } \\
\text { peanut kernels } \\
\end{array}$ & $\begin{array}{l}\text { *Total length: } \\
240 \mathrm{~mm} \\
\text { *Tip length: } 80 \mathrm{~mm} \\
\text { *Tip slant angle: } 1^{\circ}\end{array}$ & $\begin{array}{l}\text { *Food-pinching } \\
\text { performance } \\
\text { *Subjective ranking }\end{array}$ & $\begin{array}{l}\text { *Optimum handle } \\
\text { diameter: } 6 \mathrm{~mm}\end{array}$ \\
\hline $\begin{array}{l}\text { Wu and } \\
\text { Tsai (2012) }\end{array}$ & $\begin{array}{l}\text { *The way of } \\
\text { holding } \\
\text { chopsticks: pincer- } \\
\text { like, scissor-like } \\
\text { *Cross-section } \\
\text { shapes of handle: } \\
\text { circular, } \\
\text { rectangular, } \\
\text { square, hexagonal, } \\
\text { rounded square }\end{array}$ & $\begin{array}{l}\text { *Total length: } \\
230 \text { mm } \\
\text { *Tip diameter: } \\
2 \text { mm } \\
\text { *Tip length: } \\
115 \text { mm }\end{array}$ & $\begin{array}{l}\text { *Food-pinching } \\
\text { performance } \\
\text { *Performance of } \\
\text { pulling food apart } \\
\text { *Food-cutting } \\
\text { performance } \\
\text { *Subjective } \\
\text { evaluation } \\
\text { *Subjective ranking }\end{array}$ & $\begin{array}{l}\text { *Pincer-like holding } \\
\text { works best } \\
\text { *Handles of circular } \\
\text { and rounded } \\
\text { square shapes } \\
\text { work best }\end{array}$ \\
\hline Lin (2002) & $\begin{array}{l}\text { *The way of } \\
\text { holding } \\
\text { chopsticks: pincer- } \\
\text { like, scissor-like }\end{array}$ & $\begin{array}{l}\text { *Handle diameter: } \\
6 \mathrm{~mm} \\
\text { *Tip diameter: } \\
4 \mathrm{~mm}\end{array}$ & $\begin{array}{l}\text { *Food-pinching } \\
\text { performance } \\
\text { *Food-pulling force } \\
\text { *Subjective }\end{array}$ & $\begin{array}{l}\text { *Bamboo and wood } \\
\text { work better than } \\
\text { the other } \\
\text { substances; tip }\end{array}$ \\
\hline
\end{tabular}




\begin{tabular}{|c|c|c|c|c|}
\hline & $\begin{array}{l}\text { *With or without } \\
\text { carved grooves on } \\
\text { the tips }\end{array}$ & $\begin{array}{l}\text { *Tip length: } 30 \mathrm{~mm} \\
\text { *Tip slant angle: } 2^{\circ} \\
\text { *Substance: } \\
\text { bamboo, wood, } \\
\text { stainless steel, } \\
\text { plastic }\end{array}$ & $\begin{array}{l}\text { evaluation } \\
\text { *Subjective ranking }\end{array}$ & $\begin{array}{l}\text { carved grooves are } \\
\text { preferable } \\
\text { *Pincer-like holding } \\
\text { works better in } \\
\text { terms of food- } \\
\text { pinching } \\
\text { performance and } \\
\text { subjective } \\
\text { evaluation }\end{array}$ \\
\hline $\begin{array}{l}\text { Chen } \\
\text { (1998) }\end{array}$ & $\begin{array}{l}* \text { Circular handle } \\
\text { and circular tip } \\
\text { with carved } \\
\text { grooves }(1 \mathrm{~mm} \\
\text { wide and } 0.5 \mathrm{~mm} \\
\text { deep) }\end{array}$ & $*$ Tip slant angle: $2^{\circ}$ & $\begin{array}{l}\text { *Performance of } \\
\text { pulling food apart } \\
\text { *Food-pinching } \\
\text { performance } \\
\text { *Food-moving } \\
\text { performance } \\
\text { *Subjective } \\
\text { evaluation } \\
\text { *Subjective ranking }\end{array}$ & $\begin{array}{l}\text { *Circular tip with } \\
\text { carved grooves } \\
\text { works best } \\
\text { *For chopsticks } \\
\text { used at home, } \\
\text { circular handle and } \\
\text { circular tip with } \\
\text { carved grooves } \\
\text { work best } \\
\text { *For chopsticks } \\
\text { used at restaurants, } \\
\text { circular handle and } \\
\text { square tip work } \\
\text { best }\end{array}$ \\
\hline
\end{tabular}

After the reviews of other studies of chopsticks and their food-serving performance, this research focuses on the influence of chopstick lengths on food-pinching and users' subjective. It is hoped that experiments of this research will help identify the most appropriate chopstick length, and which may serve as an important guidance for manufacturers in producing chopsticks.

\section{Method}

This research was an attempt to assess the influence of different chopstick lengths on food-serving performance through experiments. The independent variables were four pairs of chopsticks of different lengths, the dependent variables were food-pinching performance and subjective evaluations, and the control variables were chopstick diameters, shapes, and substances.

\subsection{Subjects}

A total of 40 college students, $40 \%$ male and $60 \%$ female, with an average age of 22 , were invited to take part in the experiment. This research was designed to have volunteers participate in the experiment; therefore, the number of sexes was not brought under control. An additional reason was that according to some relevant studies, there are no significant differences between males and females when they use chopsticks. In the experiment of this research, subjects operated chopsticks in ways they normally do in their daily life with their habitual hands $(95 \%$ of them are right-handers and 5\% left-handers.) The experiment and its purpose were explained to subjects by the researcher in advance. After it was confirmed that all subjects understood and agreed to the experiment, they were asked to provide personal information and conduct the experiment.

\subsection{Chopsticks}

Four pairs of chopsticks of different lengths were used in the research, including $120 \mathrm{~mm}$ (Type A), $150 \mathrm{~mm}$ (Type B), $180 \mathrm{~mm}$ (Type C), and $210 \mathrm{~mm}$ (Type D). Based on results of relevant studies, it appeared that bamboo is the best substance for chopsticks as it provides more pinching accuracy regardless of people's holding methods (Lin, 2002). Therefore, bamboo was the choice of chopstick substance in the experiment. In addition to the material of bamboo, all four pairs of chopsticks had a 6 
$\mathrm{mm}$ diameter handle, a $4 \mathrm{~mm}$ diameter circular tip with $2^{\circ}$ slant angle and carved grooves (Chen, 1998).

\subsection{Instruments and materials}

Equipment used in the experiment included four pairs of chopsticks, a stopwatch, peanut kernels, a plate, and a cup. The chopsticks had a handle $6 \mathrm{~mm}$ in diameter, a circular tip $4 \mathrm{~mm}$ in diameter with shallow carved grooves (see Table 2).

Table 2. Experiment equipment and specifications.

\begin{tabular}{|l|l|l|}
\hline Item & Specifications & Quantity \\
\hline Bamboo chopsticks & $\begin{array}{l}210 \mathrm{~mm}, 180 \mathrm{~mm}, 150 \mathrm{~mm}, \text { and } 120 \mathrm{~mm} \text { in } \\
\text { length }\end{array}$ & 4 pairs \\
\hline Stopwatch & Standardized stopwatch & 1 \\
\hline Peanut kernels & $10 \mathrm{~mm}$ in diameter & Several \\
\hline Plate & $400 \mathrm{~mm}$ in diameter & 1 \\
\hline cup & $72 \mathrm{~mm}$ in diameter and $110 \mathrm{~mm}$ in height & 1 \\
\hline
\end{tabular}

\subsection{Measurements and experiment procedure}

The aim of this research was to understand the influence of chopstick lengths on the pinching performance and users' subjective evaluations, so the most appropriate chopstick length was to be judged from pinched quantity of peanut kernels and the subjective evaluation of subjects. What was measured in the experiment included (1) quantity of peanut kernels pinched by subjects given the same amount of time (larger quantity signified less time required for each pinch and easier operation of chopsticks), and (2) satisfaction level of subjects after the experiment by using a subjective preference questionnaire to understand their psychological needs. There were five satisfaction levels in the questionnaire: 5 stood for "most satisfied," and 1 stood for "least satisfied."

In preparation stage, to encourage subjects' cooperation and to smooth the process of the experiment, the researcher explained the content of the experiment and procedures in advance. Then subjects were asked to provide their basic information before starting the experiment. Before the formal experiment began, subjects were allowed to adjust their seats to the height they were comfortable with and choose a random pair of chopsticks for a one-minute practice. Once the experiment began, subjects were given chopsticks of different lengths on a random basis and were required to pinch peanut kernels from a $400 \mathrm{~mm}$ plate in front of them and put those peanut kernels in a cup ( $72 \mathrm{~mm}$ in diameter and $110 \mathrm{~mm}$ in height) placed below their mouth to simulate distance and height in real-world eating. The chopsticks were provided in random orders to eliminate the learning effect. Each test was to last for one minute, and no more pinching was allowed after the researcher gave a stop signal. Subjects had to rely solely on chopsticks with no other supplementary actions allowed during the test. To avoid fatigue, a two-minute break was arranged between consecutive tests. The experiment would count as completed only when subjects had finished the pinching test with all four sets of chopsticks of different lengths.

After the test, quantity of peanut kernels was counted by subjects, and subjects were then asked to immediately fill out a subjective evaluation questionnaire concerning their preferences (according to their level of satisfaction, a score of 1 to 5 was given, with 5 standing for "most satisfied" and 1 standing for "least satisfied").

\section{Results}

The statistical method of ANOVA was employed in the study, in which independent variables were chopsticks of four different lengths (120 mm as Type A, $150 \mathrm{~mm}$ as Type B, $180 \mathrm{~mm}$ as Type C, and $210 \mathrm{~mm}$ as Type D) and dependent variable was quantity pinched in one minute. The results 
showed a significant difference among four groups ( $\mathrm{p}=0.001)$. A follow-up Least Significant Difference (LSD) analysis showed that when the length of chopsticks changed from $120 \mathrm{~mm}$ to 180 $\mathrm{mm}$, a significant difference in quantity pinched was observed $(\mathrm{p}=0.017)$. The $180 \mathrm{~mm}$ group had the largest average quantity pinched (Mean=28.0), followed by the $210 \mathrm{~mm}$ group (Mean=26.5), the 150 $\mathrm{mm}$ group (Mean=25.6), and the $120 \mathrm{~mm}$ group (Mean=24.8). In terms of level of satisfaction, the $210 \mathrm{~mm}$ group had the highest score, and the average score decreased with length, which means that the longer chopsticks, the higher level of satisfaction found in subjects. Results are shown in Table 3 and 4.

Table 3. Pinching performance and subjective satisfaction score.

\begin{tabular}{|c|c|c|c|c|}
\hline \multirow{2}{*}{ Type } & \multicolumn{2}{|c|}{ Quantity } & \multicolumn{2}{c|}{ Satisfaction } \\
\cline { 2 - 5 } & Mean & Std. Deviation & Mean & Std. Deviation \\
\hline Type A=120 mm & 24.8500 & 5.45165 & 3.0000 & 1.08604 \\
\hline Type B=150 mm & 25.6500 & 5.75816 & 3.2750 & 1.06187 \\
\hline Type C=180 mm & 28.0250 & 5.46076 & 3.3750 & 1.25448 \\
\hline Type D=210 mm & 26.5000 & 6.82379 & 4.0500 & 1.19722 \\
\hline Total & 26.2563 & 5.96241 & 3.4250 & 1.20559 \\
\hline
\end{tabular}

Table 4. Significance in the dependent variable.

\begin{tabular}{|c|c|c|c|c|c|c|c|}
\hline \multicolumn{2}{|c|}{ Dependent Variable } & \multicolumn{3}{|c|}{ Quantity } & \multicolumn{3}{|c|}{ Satisfaction } \\
\hline (I) Type & (J) Type & $\begin{array}{c}\text { Mean } \\
\text { Difference } \\
\text { (I-J) }\end{array}$ & Std. Error & Sig. & $\begin{array}{c}\text { Mean } \\
\text { Difference } \\
(\mathrm{I}-\mathrm{J})\end{array}$ & Std. Error & Sig. \\
\hline \multirow{3}{*}{ Type A } & Type B & -0.80000 & 1.31938 & 0.545 & -0.27500 & 0.25773 & 0.288 \\
\hline & Type $\mathrm{C}$ & $-3.17500^{*}$ & 1.31938 & 0.017 & -0.37500 & 0.25773 & 0.148 \\
\hline & Type D & -1.65000 & 1.31938 & 0.213 & $-1.05000^{*}$ & 0.25773 & 0.000 \\
\hline \multirow{3}{*}{ Type B } & Type A & 0.80000 & 1.31938 & 0.545 & 0.27500 & 0.25773 & 0.288 \\
\hline & Type C & -2.37500 & 1.31938 & 0.074 & -0.10000 & 0.25773 & 0.699 \\
\hline & Type D & -0.85000 & 1.31938 & 0.520 & $-0.77500^{*}$ & 0.25773 & 0.003 \\
\hline \multirow{3}{*}{ Type C } & Type A & $3.17500^{*}$ & 1.31938 & 0.017 & 0.37500 & 0.25773 & 0.148 \\
\hline & Type B & 2.37500 & 1.31938 & 0.074 & 0.10000 & 0.25773 & 0.699 \\
\hline & Type D & 1.52500 & 1.31938 & 0.250 & $-0.67500^{*}$ & 0.25773 & 0.010 \\
\hline \multirow{3}{*}{ Type D } & Type A & 1.65000 & 1.31938 & 0.213 & $1.05000^{*}$ & 0.25773 & 0.000 \\
\hline & Type B & 0.85000 & 1.31938 & 0.520 & $0.77500^{*}$ & 0.25773 & 0.003 \\
\hline & Type $\mathrm{C}$ & -1.52500 & 1.31938 & 0.250 & $0.67500^{*}$ & 0.25773 & 0.010 \\
\hline
\end{tabular}

\section{Discussion and Conclusion}

The study proved that the length of chopsticks has a significant influence on the pinch performance. When the length of chopsticks changed from $120 \mathrm{~mm}$ to $180 \mathrm{~mm}$, a significant difference in quantity pinched was observed $(\mathrm{p}=0.017)$. In terms of the total quantity pinched, however, Type $\mathrm{C}$ worked better than the others (Types $\mathrm{A}, \mathrm{B}$ and $\mathrm{D}$ ). When it came to the subjective evaluation by subjects, the subjective level of satisfaction increased with the length of chopsticks.

On the whole, a length between 18 and 21 centimeters is recommended for the design of chopstick. In the future, the study will be extended in a larger scale and in a more randomized manner with the implement of correlation analysis. It is expected to find the most appropriate chopstick length which may serve as important information for manufacturers in mass-production of chopsticks.

Chopsticks have been an important utensil for Chinese people and some Asian people for centuries, and there are billions of chopstick users every day. This research only focused on the length 
of chopsticks, but in the future, researchers can further study the influence of the shape of chopsticks on the pinch performance (Koreans use flat chopsticks, Japanese use polygonal chopsticks, and Chinese use round chopsticks) (Chiu, 2013). Moreover, the influence of material of chopsticks on the pinch performance can be also studied.

\section{Acknowledgements}

This work was partially supported by the National Science Council, Taiwan, under the Grant No. MOST 104-2221-E-218-015-MY2; Southern Taiwan University of Science and Technology, Taiwan, under the Grant No. R105118.

\section{References}

1. M.W. Riley and D.J. Cochran, Handles for sharp tools, In Proceedings of the Symposium on Occupational Safety Research and Education, 67-74 (1980)

2. D.J. Cochran and M.W. Riley, The effects of handle shape and size on exerted force, Human Factors, 28 (3), 253-265 (1986)

3. D.J. Cochran, M.W. Riley, An evaluation of knife handle guarding, Human Factors, 28 (3), 295301 (1986)

4. S.H. Hsu and S.P. Wu, An investigation for determining the optimum length of chopsticks, Applied Ergonomics, 22 (6), 395-400 (1991)

5. T. Chan, A study for determining the optimum diameter of chopsticks, International Journal of Industrial Ergonomics, 23, 101-105 (1999)

6. S.P. Wu, Effects of the handle diameter and tip angle of chopsticks on the food-serving performance of male subjects, Applied Ergonomics, 26 (6), 379-385 (1995)

7. Y.L. Chen, Effects of shape and operation of chopsticks on food-serving performance, Applied Ergonomics, 29 (4), 233-238 (1998)

8. S.P. Wu and W.H. Tsai, Handle cross dection and chopsticks grasping mode effects on foodserving performance, Journal of Work and Leisure, 3 (1), 1-10 (2012)

9. T.F. Lin, The study of the effects of pinching operation, material of chopsticks, and carved groove on food-serving performance, Theory of Huafan University (2002)

10. Y.J. Chiu, Study of Food Culture In Japan and Taiwan- Around The Chopsticks, Theory of IShou University (2013) 